
DOIS LIVROS

\author{
- Eduardo Henrique Peiruque \\ Kickhöfel* \\ Universidade Federal de São Paulo \\ São Paulo - São Paulo - Brasil
}

Resenha dos livros: BOSI, Alfredo. Arte e conhecimento em Leonardo da Vinci. São Paulo: Edusp, 2018; e ISAACSON, Walter. Leonardo da Vinci. Rio de Janeiro: Intrínseca, 2017.

\title{
A tarefa do historiador
}

Historiadores visam compreender eventos passados. Restos de colunas sugerem um templo que eles tentam imaginar utilizando elementos preservados. Entretanto, às vezes, nem restos existem. Em sua Institutio oratoria, Quintiliano discute Virgílio e Ovídio, comenta que Macer e Lucrécio valem a leitura e, então, menciona Varrão Atacino, Cornélio Severo, Saleio Basso, Gaio Rabírio, Albinovano Pedo, Marco Fúrio Bibáculo, Lúcio Ácio, Marco Pacúvio e outros poetas que admirava. Desses autores, hoje só existem obras de Virgílio, Ovídio e Lucrécio (GREENBLATT, 2011, p. 59). Historiadores não podem imaginar autores que sequer sobreviveram enquanto nomes. Então, ao escrever, eles tentam encaixar peças fragmentadas de um quebra-cabeças cujo amplo desenho conhecem vagamente, e desconhecem suas dimensões.

\footnotetext{
* Doutor em Filosofia pela Universidade de São Paulo e professor de História da Filosofia da Renascença na Escola de Filosofia, Letras e Ciências Humanas da Universidade Federal de São Paulo. E-mail: kickhofel@hotmail.com.
} 
Existem inúmeras abordagens para estudar fragmentos de épocas passadas. No caso de documentos escritos, a História Conceitual talvez seja uma das abordagens mais importantes, pois conceitos estruturam questões de época e permitem relacionar momentos distintos. Matteo Palmieri, humanista e embaixador florentino, escreveu entre 1431 e 1438 o Libro della vita civile [Livro da vida civil], no qual fala a respeito da formação para viver dignamente em uma "ótima república":

Rápido conhecer-se-á o primeiro sinal de uma alma bem composta quando ela está firme e consigo mesma, não desviando dos primeiros engenhos, se ela considera e volta-se aos termos fundamentais de qualquer ciência ou arte, a cada dito e fato correspondendo, e sabe que qualquer outra via é vaga, instável e sem fruto. (PALMIERI, 1529, p. 28v)1

De modo mais claro, em uma disputa a respeito de artes publicada em 1549, o historiador e poeta florentino Benedetto Varchi (1859c, p. 628) diz: “Em cada disputa se deve, em primeiro lugar, para fugir de equívocos e trocas de nomes, declarar os termos principais". ${ }^{2}$ Ele declara, a seguir, os sentidos de "ciência" e "arte". Essas palavras traduzem os termos gregos epistême e têchne, respectivamente, por sua vez traduzidas por latinos por scientia e ars e, no Renascimento italiano, por scienza e arte, que não eram usadas como se usa hoje.

Quando se fala e escreve "arte", em geral essa palavra significa obra de arte. Basta pensar a respeito do Museu de Arte de São Paulo, ou seja, um museu que coleciona e expõe objetos com qualidades usualmente descritas como estéticas para serem apreciados como tais, mas não por funções ou utilidades imediatas. Nesse sentido, não obstante certas obras modernas e contemporâneas com funções políticas, arte visa contemplação e deleite. Entretanto, no Renascimento, arte era "um hábito que faz, com razão verdadeira, coisas que não são necessárias, cujo princípio não está nas coisas que se faz, mas em quem as faz", segundo Varchi (1859c, p. 629)³, que praticamente

\footnotetext{
1 "Tosto si conoscerà il primo segno dell'animo bene composto essere stare fermo et seco medesimo, non deviando da' primi ingegni, considerare e rivolgere i termini fondamentali di qualunche scienza o arte, et a quegli con ogni detto et facto conrispondere, sappiendo che ogni altra via è vaga e instabile et sanza fructo". As traduções são do autor deste artigo, excetuando a tradução da nota 11.

2 "In ciascuna disputa si debbe la prima cosa, per fuggire l'equivocazione e scambiamento dei nomi, dichiarare i termini principali."

3 "L'arte è uno abito fattivo con vera ragione, di quelle cose, che non sono necessarie, il principio delle quali non è nelle cose che si fanno, ma in colui che le fa". A definição de Aristóteles está na Ética Nicomaqueia (Et. Nic., VI, 1140a).
} 
traduz a definição que está nas discussões éticas de Aristóteles. Dito de outro modo, arte era conhecimento prático, e quem tinha arte produzia discursos, pinturas e esculturas, máquinas de guerra e uma miríade de objetos cotidianos. ${ }^{4}$ Além disso, no Renascimento, existiam artífices, ou seja, homens que produziam obras seguindo encomendas e contratos. Artistas, em princípio, expressam subjetividades, tendo esse tipo surgido no Romantismo, tal qual ideias a respeito de obra de arte. ${ }^{5}$ De modo semelhante, quando hoje se usa a palavra "ciência", consideram-se conhecimentos descritivos obtidos a partir de observações controladas e/ou experimentos, cujos resultados são tratados matematicamente e dos quais se faz teorias que predizem fenômenos semelhantes. Nesse sentido, a despeito de ciências como a cosmologia, ciências naturais visam aplicações sob a forma de tecnologias e produtos tecnológicos. Entretanto, citando outra vez Varchi (1859c, p. 628), ciência era "a cognição das coisas universais e necessárias, e consequentemente eternas, tidas mediante demonstração", de novo uma definição aristotélica. ${ }^{6}$ Dito de outro modo, ciência era conhecimento teórico, vindo de experiências comuns e subordinado a concepções metafísicas de noções universais que visava contemplação. Além disso, no Renascimento, existiam filósofos naturais e matemáticos, tipos distintos devido ao fato que a física e a matemática eram disciplinas separadas. Cientista, vale dizer, é um tipo profissional surgido no século XIX. ${ }^{7}$ Eis os sentidos correntes no Renascimento e atestados por dezenas de fontes escritas. Não por acaso, "arte" e "ciência" são mencionadas por Palmieri

\footnotetext{
${ }^{4}$ A palavra "arte" também era usada para descrever ofícios ou profissões, sentido também presente em textos antigos. O pintor Cennino Cennini, autor do tratado Il libro dell'arte [O livro da arte], escrito por volta de 1400, deixa claro esses dois sentidos no Renascimento. No primeiro capítulo, Cennini (2003, p. 61-63) se diz como "picholo membro essercitante nell'arte di dipintoria", ou seja, membro do ofício ou da profissão da pintura, e então, ao elogiar o pintor Giotto di Bondone, ele diz que Giotto "ebbe l'arte più compiuta che avessi mai più nessuno", ou seja, Giotto teve conhecimentos práticos para pintar melhor do que qualquer outro antes dele.

${ }^{5}$ Não é problema fazer história da arte renascentista, desde que se saiba que se usa conceitos ainda não existentes naquele período. Imagine a surpresa de um homem do século XV na seção renascentista da National Gallery de Londres, vendo pinturas religiosas em um edifício secular dispostas de modo para ele incompreensível e em frente às quais pessoas não rezam, mas fazem selfies etc.

6 "Scienza non è altro che la cognizione delle cose universali e necessarie e conseguentemente eterne, avuta mediante la dimostrazione." A definição de Aristóteles está na Ética Nicomaqueia (Et. Nic., VI, 1139b).

7 A palavra como se usa hoje vem de Whewell (Snyder, 2017): "In response to a challenge by the poet S.T. Coleridge in 1833, Whewell invented the English word "scientist;" before this time the only terms in use were 'natural philosopher' and 'man of science'".
} 
e Varchi como um pare, como tal, está em prefácios de fontes tão diversas como Della pittura [Da pintura], de Leon Battista Alberti, De humanis corporis fabrica [Da estrutura do corpo humano], de Andreas Vesalius, General trattato di numeri et misure [Tratado geral de números e medidas], de Niccolò Tartaglia e Discorsi e dimostrazioni matematiche intorno a due nuove scienze [Discursos e demonstrações matemáticas em torno a duas novas ciências], de Galileu Galilei, entre outros. Arte e ciência marcam a oposição entre conhecimentos práticos e teóricos. Quanto mais afastados da matéria, mais precisos e menos úteis, mais nobres eram os conhecimentos:

Todas as ciências, estando na razão superior [do intelecto] e tendo o fim mais nobre, isto é, contemplar, são sem dúvida alguma mais nobres que todas as artes, as quais estão na razão inferior e tem o fim menos nobre, isto é, operar. (VARCHI, 1859c, p. 628)8

Aliás, arte e ciência estavam colocadas sob a noção ampla de filosofia, no sentido de conhecimentos sistematizados por princípios e causas que podiam ser ensinados. Nos termos da época, filosofia era "o conhecimento de coisas humanas e divinas juntamente com o estudo de bem viver". A palavra "filosofia", vale dizer, não era usada no sentido de doutrinas de certos filósofos (p.e. filosofia aristotélica ou kantiana), períodos históricos consolidados aproximadamente no último século e meio (p.e. filosofia grega ou moderna) ou tendências contemporâneas (p.e. filosofia analítica ou continental). De múltiplos modos, somos herdeiros do século XVIII e das disciplinas formadas nos séculos XIX e XX. Por isso, e historiadores do Renascimento visam eliminar uma espécie de "filtro romântico" para articular questões daquela época e, assim, não tentar encaixar círculos em quadrados.

Inevitavelmente, historiadores são anacrônicos em relação a eventos passados que estudam, mas eles podem evitar termos muito comprometidos com suas próprias épocas. Evitar palavras como "arte" e "ciência" talvez requeira esforços inúteis, então resta explicar seus usos lá e cá. Porém, historiadores podem evitar diversas outras, como "artista" e "cientista". Nesse sentido, vale recordar Nikolaus Harnoncourt, regente e teórico que, na segunda metade do século passado, começou a interpretar peças musicais bar-

\footnotetext{
8 "Tutte le scienze, essendo nella ragione superiore et avendo più nobile fine, cioè contemplare, sono senza alcuno dubbio più nobili di tutte l'arti, le quali sono nella ragione inferiore et hanno men nobile fine, cioè operare."

9 Como diz Gregor Reisch (1503, fol. 4v): "Philosophia est divinarum humanarumque rerum cognitio cum studio bene vivendi coniuncta". Varchi (1859b) e Franciscus Toletus (1574), entre tantos outros autores, apontam para definições semelhantes derivadas de textos antigos.
} 
rocas a partir de estudos de fontes de época. Questionado por musicólogos a respeito da impossibilidade de saber como se interpretava música na época de Johann Sebastian Bach, ele respondia: "Certo, não sabemos precisamente como era, mas sabemos muito precisamente como não era". ${ }^{10}$

Isto posto, considera-se, nesta resenha, dois livros a respeito de Leonardo da Vinci recentemente lançados no país. O primeiro chama-se Arte e conhecimento em Leonardo da Vinci, do professor emérito de literatura brasileira da Faculdade de Filosofia, Letras e Ciências Humanas da Universidade de São Paulo e imortal da Academia Brasileira de Letras, Alfredo Bosi. O segundo, Leonardo da Vinci, do escritor Walter Isaacson, autor das biografias de Benjamin Franklin e Steve Jobs, entre outras.

\section{Alfredo Bosi: arte e conhecimento em Leonardo da Vinci}

O livro de Alfredo Bosi, pequeno em termos de dimensões e de edição cuidada, elenca ao longo de aproximadamente oitenta páginas argumentos a respeito de diversas matérias tratadas por Leonardo da Vinci, como as seções "Anatomias", "O fabulário" e "Desenho/pintura", entre outras, sem uma direção argumentativa clara.

Bosi não é historiador do Renascimento italiano, mas espera-se rigor de um crítico e historiador da literatura brasileira de larga experiência e currículo. Infelizmente, seu livro não mostra isso. A bibliografia sugere pouca intimidade com estudos atualizados a respeito de Leonardo e do Renascimento italiano. Bosi não consultou as edições de referência da Giunti, mas sim três compilações de textos de Leonardo, e não expressa conhecer fontes do período, por exemplo textos de Alberti, autor fundamental para entender as artes no século XV em Florença. Bosi também não cita textos importantes de estudiosos contemporâneos, como Martin Kemp e Pietro Marani, e não cita compêndios editados no mundo anglo-saxão, como os volumes editados pela Cambridge University Press. Assim, Bosi não contextualiza os termos principais, ou seja, "arte" e "ciência", e escreve palavras anacrônicas como "artista" e "cientista" para qualificar Leonardo. Também lança mão de conceitos anacrônicos como "realismo fenomenológico", "inconsciente" e "a teoria estética de Leonardo", sem qualificá-los. Além disso, ele repete ideias de meados do século XX, como dizer que a filosofia renascentista italiana

\footnotetext{
10 "Certes nous ne savons pas exactement comment c'était, mais nous savons très exactement comment ce n'était pas". Citado por Reinhard Goebel. Diapason n. 645, avril 2016.
} 
foi principalmente neoplatônica, ao passo que, não obstante a importância do neoplatonismo (mais precisamente, do neoneoplatonismo) florentino de Marsilio Ficino, hoje se sabe que a filosofia do período foi predominantemente aristotélica (BIANCHI, 2007; KUHN, 2018; SCHMITT, 1983). Assim, se diversas páginas apresentam belas passagens de um crítico sensível a obras de arte, eis o texto de um autor que pouco conhece a matéria sobre a qual escreve e que não resolve a questão que propõe no título: arte como conhecimento. Seria relativamente simples organizar questões em torno desse conceito conforme está em fontes de época, como escrito acima; arte era, justamente, uma forma de conhecimento. Bosi não expressa conhecê-lo.

Talvez Bosi tenha almejado escrever um ensaio, ou seja, uma interpretação da obra de Leonardo não diretamente dependente de estudos acadêmicos, como sugere a ausência de notas de rodapé. Ser explicitamente anacrônico pode ser uma opção de escrita que talvez tenha resultados importantes. Nesse sentido, talvez a maior falha do livro seja não esclarecer qual é seu objetivo. Um prefácio resolveria facilmente a questão, tal como se fazia no Renascimento, em uma tradição que vinha dos antigos, como diz Varchi (1859a, p. 807):

E, de verdade, quem não sabe o fim onde quer e deve suceder, mal poderá fornecer e se obter daqueles meios que a tal fim o conduzam; e, porém, dizia Alexandre, muito excelente peripatético, aqueles os quais não sabem a intenção são similares a um cego que não sabe onde se vai, e ainda assim parte. ${ }^{11}$

\section{Walter Isaacson: Leonardo da Vinci}

Walter Isaacson escreveu uma biografia de Leonardo da Vinci que, na versão digital, tem mais de mil páginas. A vida de Leonardo é explorada cronologicamente, e o autor aproveita etapas de sua vida para aprofundar certos temas, como nos capítulos "Cientista", "Artes mecânicas" e "Matemática".

Isaacson também não é historiador e seu currículo mostra um escritor de divulgação. Entretanto, ele tem formação em História e Literatura em Harvard e, hoje, é professor na Tulane University, em New Orleans. Isaacson

\footnotetext{
11 "E divero chi non sa il fine dove voglia e debbia riuscire, male potrà provvedere e procacciarsi di quei mezzi che a tal fine lo conducano; e però diceva Alessandro eccellentissimo Peripatetico, quegli i quali non sanno l'intenzione, sono simili a un cieco che non sa ove si vada, e pur si parte". Tradução inédita de Iryna Dhamen Carbonero.
} 
fez uma ampla pesquisa, pois os agradecimentos do livro mostram que ele conversou com estudiosos e consultou textos de referência para construir a narrativa. Entretanto, intimidade com uma dada área de pesquisa requer anos de estudo. Isaacson deixou textos importantes de lado, inclusive a respeito do Renascimento, e usa escritores irrelevantes para estudos acadêmicos, como Serge Bramly, autor de uma biografia relativamente popular publicada vinte anos atrás.

Isaacson chama o físico new age Fritjof Capra de "historiador" e, mesmo que negue a ideia de Capra a respeito de Leonardo da Vinci escrita em uma biografia recente, qual seja que Leonardo teria sido o pai da ciência moderna se ele tivesse publicado seus manuscritos ou se estes tivessem sido estudados após sua morte, Isaacson diz repetidamente que tal e tal descoberta de Leonardo só foi redescoberta séculos após. Isaacson paga tributo a um mito duro de matar: "Leonardo era um gênio, mas não só isso: ele era a epítome de uma mente universal, que se esforçou para entender por completo a criação de tudo, incluindo o lugar que ocupamos nela" (ISAACSON, 2017, p. 1014). Leonardo não era um gênio, conceito do século XVIII, mas teve engenho (no sentido de talento natural) e arte (no sentido de conhecimentos). Também, Leonardo não era "o homem universal do Renascimento". Leonardo teve interesse em áreas específicas, por exemplo em matemática e física, mas não em metafísica, e em algumas artes, mas não em ética e política. Isaacson também não define os termos principais, especialmente "arte" e "ciência". Como no caso de Bosi, também chama Leonardo de "artista" e "cientista". Além disso, ele não resiste a questões anedóticas. Em dezenas de passagens, ele julga conhecer afetos de Leonardo, por exemplo no seguinte trecho (p. 117): "Leonardo gostava tanto da atmosfera familiar e colaborativa do ateliê de Verrocchio que, quando seu aprendizado chegou ao fim, em 1472, aos vinte anos, ele decidiu permanecer trabalhando e morando lá" (ISAACSON, 2017, p. 1014). Talvez esse tipo de narrativa funcione em um livro de divulgação, mas esse modo de escrever leva Isaacson (2017, p. 440) a fazer afirmações não baseadas em documentos, como ao falar dos primeiros estudos anatômicos de Leonardo: “Em pouco tempo, proeminentes acadêmicos de anatomia passaram a atuar como seus tutores, primeiro emprestando livros e depois ensinando a dissecação". Não existem documentos conhecidos ou publicados que mostrem isso. ${ }^{12}$ Por fim, ele abre mão da seriedade no capí-

\footnotetext{
${ }^{12}$ Cf. Villata (1999), a mais abrangente publicação de documentos a respeito de Leonardo não citada por Isaacson.
} 
tulo final ao elencar tópicos chamados de "aprendendo com Leonardo": "seja curioso, incansavelmente curioso", "busque o conhecimento pelo simples prazer da busca", "conserve a capacidade das crianças de se maravilhar" etc. Isaacson, aqui, lembra livros de autoajuda.

Talvez a maior falha do livro seja não esclarecer qual seu objetivo, mas, agora, em outro sentido. Isaacson não escreveu uma biografia acadêmica, mas como livro de divulgação talvez ele seja excessivamente longo. A que público ele quer agradar? A ideia de biografias de inovadores talvez seja interessante, como ele diz logo no início: "Embarquei neste livro porque Leonardo da Vinci é o exemplo definitivo do tema central de minhas biografias anteriores: como a habilidade de conectar disciplinas - artes e ciências, humanidades e tecnologia - é a chave para a inovação, imaginação e genialidade" (ISAACSON, 2017, p. 29). Entretanto, colocar na mesma perspectiva Leonardo da Vinci, Benjamin Franklin e Steve Jobs, entre outros, requer cuidados conceituais. Artes e ciências fazem sentido ao se falar do Renascimento, mas não humanidades e tecnologia, porque as artes e ciências da época de Steve Jobs, por exemplo, fazem parte de um contexto cultural muito diverso da civiltà do Renascimento. 


\section{Observações finais}

Textos acadêmicos a respeito de Leonardo também não definem termos básicos como "ciência" e "arte", entre outros. Bosi e Isaacson, cada qual a seu modo, repetem essa espécie de senso comum acadêmico. ${ }^{13}$ Talvez isso se deva ao fato de que historiadores da arte, que estão entre os estudiosos que mais se dedicam à obra de Leonardo, não lidam com questões conceituais, ao passo que historiadores da filosofia e da ciência têm pouco interesse por um sujeito que não foi filósofo nem filósofo natural. Leonardo da Vinci está em uma espécie de limbo, afinal historiadores de diversos tipos ainda não responderam uma questão central: se Leonardo foi efetivamente um "gênio" e juntou "arte" e "ciência", por que motivo ele morreu isolado e sem seguidores diretos? No quadro conceitual da época, vindo em grande parte dos an-

\footnotetext{
${ }^{15}$ Cito apenas poucos exemplos recentes. No início do verbete "Science and art" no The Dictionary of Art, Kemp (1996, p. 199), o mais importante leonardista contemporâneo, define ciência e arte antes da Era Moderna em termos muito simples: "During earlier period, 'science' (Lat. scientia) meant a systematic body of knowledge constructed on rational principles, and 'art' referred to an activity requiring the steady acquisition of skill". Em círculos letrados, ciência não era um corpo de conhecimento, mas a "cognição das coisas universais e necessárias, tidas mediante demonstração", ou simplesmente um "hábito demonstrativo", e a arte não era uma atividade, mas um "um hábito que faz com razão verdadeira", seguindo as definições de Aristóteles. De fato, a palavra "ars" pode ser traduzida por "skill", de modo que a definição de Kemp de arte não é apenas errada, mas também é circular. No entanto, de acordo com o léxico grego-inglês, as fontes gregas também apontam para a ideia de "têchne" não apenas como "skill, craft in workmanship, cunning of hand" e "a set of rules or regular method of making or doing", mas também como "craft or trade". Além disso, o Merriam-Webster define "activity" como "a qualidade ou o estado de ser ativo" e como "an organizational unit for performing a specific function; also its function or duties". Nesse sentido, a definição de arte de Kemp como uma "activity" está correta, mas ele não considera arte como uma forma de conhecimento e, assim, não pode comparar arte com ciência sob o quadro conceitual comum presente no Renascimento. A grande monografia de Kemp (2006) trata de questões específicas aristotélicas, mas não elabora ideias de arte e ciência em textos aristotélicos editados, estudados e comentados no Renascimento, de modo que ele usa sistematicamente as palavras anacrônicas citadas. Papa (2005) propõe uma interpretação da "scienza della pittura" de Leonardo, mas ele não apresenta discussões sobre arte e ciência baseadas em fontes antigas, pois a única fonte antiga citada é Vitrúvio. Focando nos estudos anatômicos de Leonardo, Laurenza (2001) afirma na introdução de seu livro De figura umana que, por "chiarezza espositiva", o uso dos termos "arte e scienza è quello moderno, differente dall'accezione che le due parole avevano all'epoca di Leonardo". No entanto, ele não explica o sentido moderno dos conceitos e suas definições em relação ao Renascimento são bastante simples, pois ele qualifica a arte como "manualità, pratica empirica" e a ciência como "teoria, indipendentemente dal campo cui poteva applicarsi".
} 
tigos, artes e ciências eram essencialmente diversas entre si e, se era possível aproximá-las, como no caso da perspectiva usada por pintores e escultores, identificá-las como Leonardo quis não era possível. História Conceitual pode resolver esse tipo de questão.

\section{Referências bibliográficas}

BIANCHI, Luca. Continuity and change in the Aristotelian tradition. In: HANKINS, James (ed.). The Cambridge companion to Renaissance philosophy. Cambridge: Cambridge University Press, 2007, p. 49-71.

CENNINI, Cennino. Il libro dell'arte. Vicenza: Neri Pozza Editore, 2003.

GREENBLAT, Stephen. The Swerve: how the world became modern. New York: W. W. Norton \& Company, 2011.

KEMP, Martin. Science and art. In: TURNER, Jane (ed.). The dictionary of art. London: Macmillan Publishers, 1996, v. 28, p. 199-208.

KEMP, Martin. Leonardo da Vinci: the marvellous works of nature and man. Oxford: Oxford University Press, 2006.

KUHN, Heinrich. Aristotelianism in the Renaissance. In: ZALTA, Edward N. (ed.). The Stanford Encyclopedia of Philosophy. Stanford: Stanford University, 2018. Disponível em: <https://plato.stanford.edu/archives/spr2018/entries/aristotelianism-renaissance/>. Acesso em: 01 Julho 2019.

LAURENZA, Domenico. De figura umana: fisiognomica, anatomia e arte in Leonardo. Firenze: Leo Olschski, 2001.

PALMIERI, Matteo. Libro della vita civile. Firenze: Philippo di Giunta, 1529.

PAPA, Rodolfo. La "scienza della pittura" di Leonardo. Milano: Medusa, 2005.

REISCH, Gregor. Margarita philosophica. Friburgi: Iohannes Schottun, 1503.

SCHMITT, Charles B. Aristotle and the Renaissance. Cambridge: Harvard University Press, 1983.

SNYDER, Laura J. William Whewell. In: ZALTA, Edward N. (ed.). The Stanford Encyclopedia of Philosophy. Stanford: Stanford University, 2017. Disponível em: $<$ https://plato. stanford.edu/archives/win2017/entries/whewell/>. Acesso em: 01 Julho 2019.

TOLETUS, Franciscus. Commentaria una cum Quaestionibus in Octo Libros Aristotelis de Physica Auscultatione. Coloniae Agrippinae: Haeredes Arnoldi Birckmani, 1574.

VARCHI, Benedetto. Dei prolegomini o precognizioni. In: VARCHI, Benedetto. Opere di Benedetto Varchi. Trieste: Sezione Letterario-Artistica del Lloyd Austriaco, 1859a, v. 2, p. 805-812.

VARCHI, Benedetto. Divisione della filosofia. In: VARCHI, Benedetto. Opere di Benedetto Varchi. Trieste: Sezione Letterario-Artistica del Lloyd Austriaco, 1859b, v. 2, p. 794-796. 
VARCHI, Benedetto. Sopra la pittura e scultura: lezione due. In: VARCHI, Benedetto. Opere di Benedetto Varchi. Trieste: Sezione Letterario-Artistica del Lloyd Austriaco, 1859c, v. 2, p. 611-647.

VILLATA, Edoardo. Leonardo da Vinci. I documenti e le testimonianze contemporanee. Milano: Ente Raccolta Vinciana, 1999.

Recebido: 19/06/2019 - Aprovado: 26/08/2019

Editores responsáveis:

Júlio Pimentel Pinto e Flavio de Campos 